\title{
Unnatural death in the elderly: a retrospective study of medicolegal autopsies in Northern Tunisia
}

Mohamed Yassine Braham ${ }^{*}$ (D), Mariem Gharbeoui, Mohamed Bellali, Haithem Attia, Hana Harzallah, Olfa Bekir, Moncef Hamdoun and Mohamed Allouche

\begin{abstract}
Background: The growing proportion of elderly implies that natural and unnatural deaths of the elderly will be increasingly confronted. The objective of our study was to determine the unnatural manner and causes of death in the elderly, defined as individuals at least 65 years of age at the time of death. We conducted a monocentric restrospective study based on police investigation reports and medicolegal autopsy reports collected from the Department of Legal Medicine of Charles Nicolle Hospital in Tunis, Tunisia between January 1st, 2016 and December 31st, 2017.

Results: During this period, 3837 autopsies were performed. Five hundred ninety-two (15.4\%) were 65 years or older at the time of death. Of these, 264 deaths were categorized as accidental, suicidal, homicidal, or unknown. The mean age of victims was 75.3 years $( \pm 6.7)$, unnatural deaths were higher in urban areas $(64 \%)$ and victims were living alone in $24.7 \%$ of cases. Accidents accounted for the majority of unnatural deaths (90.5\%) and were more common in males. Traffic accidents accounted for $66.9 \%$ of accidental deaths; they were more frequent in pedestrians and more frequent on Monday. They were followed by accidental falls which accounted for $17.2 \%$ of accidents and occurred in the home especially or in the workplace. Charcoal brazier was incriminated in 11 cases of accidental thermal burns and in all cases of accidental carbon monoxide poisoning. Suicide and homicide were uncommon manners of death; they were observed in 16 and eight cases respectively. Hanging was the most used suicidal mean. Suicides were more common in males; they took place especially in the victim's home, and history of psychiatric disorders was frequently elicited.

Conclusions: Autopsies provide important statistical data that can be used for preventive strategies. For instance, actions must be carried out on the maintenance of public roads and raising awareness among public road users. Preventive measures should also include home improvement to help the elderly avoid accidental falls, installing smoke detectors, and the non-use of defective or rudimentary heating.
\end{abstract}

Keywords: Elderly suicide, Elderly accident, Elderly homicide, Forensic pathology, Cause of death, Unnatural death

\section{Background}

Longer life expectancy is one of the most important advances in medicine. According to the World Health Organization, global life expectancy at birth is 71.4 years in 2015 and 70 years in 2011 compared to 64 years in 1990 and much lower in the past (WHO 2013). Therefore, populations are rapidly aging. The current population of Tunisia is 11.6 million; the elderly represented about $11 \%$ in 2014. This ratio will reach $15 \%$ in 2025 with the increase

\footnotetext{
* Correspondence: brahammedyassine@gmail.com

Department of Legal Medicine, Charles Nicolle Hospital, Boulevard du 9 avril 1938 Bab Saâdoun, 1007 Tunis, Tunisia
}

in life expectancy which will be 80 years in 2029 compared to 74.7 in 2010 (National Institute of Statistics Tunisia 2014). The growing proportion of elderly implies that health care resources will have to be transferred to this part of the population in the future. It also implies that natural and unnatural deaths of the elderly will be increasingly confronted. In fact, deficiencies, functional decline, and loss of autonomy during this period of life make elderly subjects vulnerable and exposed to death in general and more specifically to accidents, suicides, and homicides (Eilertsen et al. 2006; Chan et al. 2007; Coelho et al. 2010). These unnatural deaths raise medicolegal issues but are 
also of considerable medical and social significance. They are the source of questions about the causes, the risk factors, and the particular circumstances surrounding them.

In order to obtain reliable information about these deaths and to allow a better knowledge of the phenomenon, it is necessary to study the results of forensic autopsies. In this way, preventive strategies can be developed. The objective of our study was to determine the unnatural manner and causes of death in older people, defined as individuals of at least 65 years of age at the time of death.

\section{Materials and methods}

We conducted a monocentric retrospective study. The data was collected from the police investigation reports and the medicolegal autopsy reports from the Department of Legal Medicine of Charles Nicolle Hospital in Tunis, Tunisia between January 1st, 2016 and December 31st, 2017. The inclusion criteria were that the deceased was 65 years or older at the time of death and that the manner of death was considered unnatural upon forensic autopsies. Our study was carried on a representative sample of the Tunisian population. In fact, $42 \%$ of the Tunisian population is located in the ten governorates of northern Tunisia and for this population, postmortem examinations are performed in the Department of Legal Medicine of Tunis where the study were conducted. Pre-existing health conditions, based on information from family and friends, were recorded from the police reports and medical records. Premortem diagnoses were categorized into cardiovascular, pulmonary, cerebrovascular, neurological, cancerous, psychiatric, and finally alcohol and drug abuse. Results from toxicological analyses were also recorded. The manner of death was registered as accidental, suicidal, homicidal, or unknown.

The statistical package SPSS for Windows, version 20.0 was used in the analyses of the results.

\section{Results}

Of the 3837 forensic autopsies performed in that period, $592(15.4 \%)$ were 65 years or older at the time of death. Of these, 264 deaths were categorized as accidental, suicidal, homicidal, or unknown. The manner of death was natural in the rest of the cases. Table 1 below illustrates the distribution of unnatural deaths epidemiological data. Accidents accounted for the majority of unnatural deaths with $90.5 \%(n=239)$. Men accounted for $74.6 \%(n=197)$ and the mean age was 75.3 years $( \pm 6.7)$. Specifically, the mean age of victims was $76( \pm 4.3)$ in accidental deaths,

Table 1 Distribution of unnatural deaths epidemiological data

\begin{tabular}{|c|c|c|c|c|c|}
\hline & Accidents & Suicide & Homicide & Unknown & Total $n(\%)$ \\
\hline Number of cases & 239 & 16 & 8 & 1 & 264 \\
\hline \multicolumn{6}{|l|}{ Gender } \\
\hline Male & 177 & 12 & 7 & 1 & 197 (74.6\%) \\
\hline Female & 62 & 4 & 1 & 0 & 67 (25.4\%) \\
\hline Mean age & $76( \pm 4.3)$ & $71.1( \pm 5.5)$ & $73.2( \pm 7.2)$ & 76 & $75.3( \pm 6.7)$ \\
\hline \multicolumn{6}{|l|}{ Occupation } \\
\hline Retired & 167 & 10 & 5 & - & 182 (68.9\%) \\
\hline Day laborer & 73 & 6 & 3 & 1 & 82 (31.1\%) \\
\hline \multicolumn{6}{|l|}{ Marital status } \\
\hline Single & 47 & 1 & 1 & 0 & 49 (18.6\%) \\
\hline Married & 181 & 12 & 5 & 1 & 199 (75.4\%) \\
\hline Widower & 5 & 2 & 1 & 0 & $8(3 \%)$ \\
\hline Divorced & 6 & 1 & 1 & 0 & $8(3 \%)$ \\
\hline \multicolumn{6}{|l|}{ Origin } \\
\hline Urban & 154 & 12 & 3 & 0 & 169 (64\%) \\
\hline Rural & 85 & 4 & 5 & 1 & 95 (36\%) \\
\hline \multicolumn{6}{|l|}{ Organic disease history } \\
\hline Cardiovascular disease & 57 & - & - & - & $70(26.5 \%)$ \\
\hline Pulmonary disease & 13 & - & - & - & \\
\hline \multicolumn{6}{|l|}{ Mental disease history } \\
\hline Depression & 3 & 5 & - & - & $16(6 \%)$ \\
\hline Schizophrenia & - & 4 & - & - & \\
\hline Dementia & 3 & 1 & - & - & \\
\hline
\end{tabular}


$71.1( \pm 5.5)$ in suicides, and $73.2( \pm 7.2)$ in homicides. Then, $68.9 \%(n=182)$ of the victims were retired and $31.1 \%(n=82)$ were day laborers. Further, $24.6 \%(n=65)$ of the victims were living alone (single, widower, or divorced). Unnatural deaths were higher in urban areas $(n=$ $169 ; 64 \%)$. Pre-existing health conditions were found in 86 (32.9\%) victims. Organic disease history were only found in victims of accidents, in fact $23.8 \%(n=57)$ of them had cardiovascular disease and $5.4 \%(n=13)$ had pulmonary disease. As for mental disease history, it concerned 6\% ( $n$ $=16)$ of the victims.

\section{Accidental deaths}

Among accidental deaths, traffic accidents accounted for $66.9 \%(n=160)$, followed by falls which accounted for $17.2 \%(n=41)$. The number and gender of victims for each type of accident is represented in Fig. 1.

Regarding traffic accidents, we found a male predominance $(n=120 ; 75 \%)$; the mean age of victims was 75.9 $( \pm 6.6)$ and the mean age for men and women was 75.5 years $( \pm 6.4)$ and 77.3 years $( \pm 7.4)$ respectively. Sixty percent $(n=96)$ lived in urban areas. Pedestrians accounted for $75 \%(n=120)$. Table 2 illustrates traffic accidents epidemiological data.

Pedestrians were older than drivers (76 vs. 72$)$ and significantly older than motorcyclists (76 vs. 72$)(p<0.05)$. Traffic accidents were more frequent on Monday $(n=60$, $37.5 \%)$. One hundred four victims died in the hospital after a short period of time not exceeding $48 \mathrm{~h}$. One victim died of pulmonary embolism after being discharged from the hospital. Forty (25\%) victims had a history of cardiovascular disease and 13 (8.1\%) had a history of chronic obstructive pulmonary disease.
Sixty-five victims died as a result of domestic accidents which represented $27.2 \%$ of accidental deaths. Domestic accidents epidemiological data is illustrated in the Table 3. The causes were falls, thermal burns, and carbon monoxide poisoning. The mean age of victims was 75.7 years $( \pm 6.8)$. Thirty-three $(50.8 \%)$ victims were living alone (single, divorced, or widower). Domestic accidents occurred mostly in winter $(n=29,44.6 \%)$. Seventeen (26.2\%) victims had cardiovascular diseases and six (9.2\%) victims had a psychiatric history including three cases of dementia.

Falls occurred in 38 cases. Falls circumstances are illustrated in Table 4 . Traumatic injuries were dominated by head trauma $(n=33)$ followed by pelvic trauma $(n=5)$. Death was secondary to pulmonary embolism during hospital stay in four cases. Falls occurred on the stairs in all cases. Thermal burns caused by flames were observed in 20 cases, Table 5 highlights their characteristics and circumstances. All these cases were third-degree burns that ranged from 20 to $80 \%$ of the body surface area, with an average of $34 \%$. The burned body parts involved the trunk, the head, and the neck in 12 cases. The brazier was incriminated in 11 cases and the source of fire was the deflagration of a gas cylinder in six cases. In three cases, the victim's sheets caught fire in contact with a cigarette. Carbon monoxide poisoning was observed in seven cases. In six of these cases, three couples were found deceased together in their home. Poisoning was attributed to gas leakage from a coal brazier in an enclosed area in all cases. The results of the toxicological analyses showed carboxyhemoglobin concentrations above $50 \%$ in all cases.

Accidents in the workplace were objectified in five male construction workers: three fell from height and two died of blunt trauma after a wall collapsed on them. Accidental

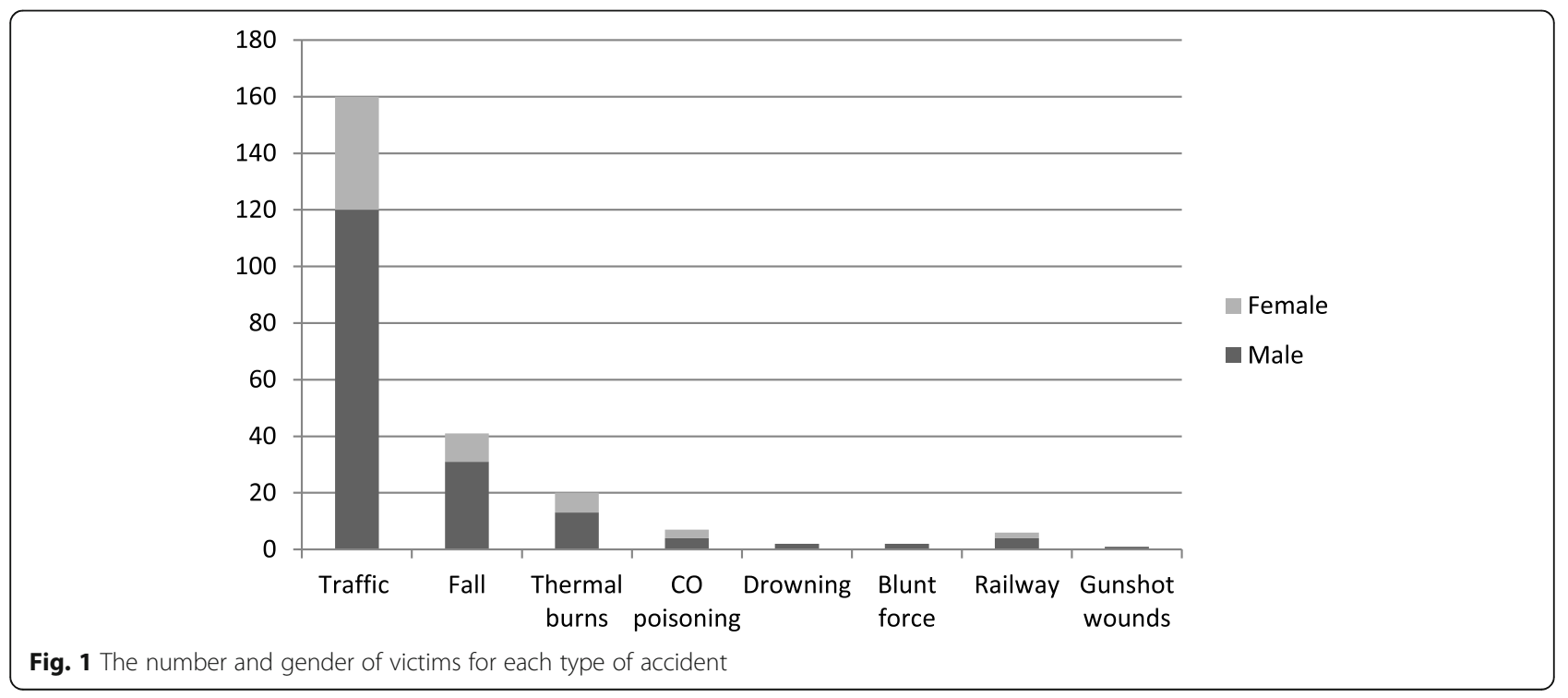


Table 2 Distribution of traffic accidents epidemiological data

\begin{tabular}{|c|c|c|c|c|c|c|}
\hline & Pedestrian $n(\%)$ & Motorcyclist $n(\%)$ & Vehicle driver $n(\%)$ & Passenger $n(\%)$ & Pedal cyclist $n(\%)$ & Total $n(\%)$ \\
\hline Number of cases & $120(75 \%)$ & $16(10 \%)$ & $8(5 \%)$ & $11(6.9 \%)$ & $5(3.1 \%)$ & 160 \\
\hline \multicolumn{7}{|l|}{ Gender } \\
\hline Male & 85 & 16 & 8 & 6 & 5 & $120(75 \%)$ \\
\hline Female & 35 & 0 & 0 & 5 & 0 & $40(25 \%)$ \\
\hline \multicolumn{7}{|l|}{ Age } \\
\hline $65-69$ & 21 & 5 & 3 & 2 & 1 & $32(20 \%)$ \\
\hline $70-74$ & 27 & 6 & 1 & 2 & 2 & 38 (23.8\%) \\
\hline $75-79$ & 34 & 3 & 2 & 3 & 1 & $43(26.9 \%)$ \\
\hline $80-84$ & 22 & 2 & 2 & 1 & 1 & $28(17.5 \%)$ \\
\hline$\geq 85$ & 16 & 0 & 0 & 3 & 0 & 19 (11.8\%) \\
\hline Mean age & $76( \pm 6.5)$ & $72.5( \pm 4.8)$ & $72( \pm 6.6)$ & $77( \pm 7)$ & $74.6( \pm 6.3)$ & $75.9( \pm 6.6)$ \\
\hline \multicolumn{7}{|l|}{ Origin } \\
\hline Urban & 77 & 7 & 3 & 6 & 3 & $96(60 \%)$ \\
\hline Rural & 43 & 9 & 5 & 0 & 2 & $64(40 \%)$ \\
\hline \multicolumn{7}{|l|}{ Day of death } \\
\hline Monday & 46 & 7 & 4 & 3 & 0 & $60(37.5 \%)$ \\
\hline Tuesday & 12 & 3 & 0 & 2 & 1 & $18(11.2 \%)$ \\
\hline Wednesday & 8 & 0 & 1 & 0 & 2 & $11(6.9 \%)$ \\
\hline Thursday & 10 & 2 & 1 & 3 & 1 & $17(10.7 \%)$ \\
\hline Friday & 16 & 1 & 2 & 1 & 0 & $20(12.5 \%)$ \\
\hline Saturday & 19 & 2 & 0 & 2 & 1 & $24(15 \%)$ \\
\hline Sunday & 9 & 1 & 0 & 0 & 0 & $10(6.2 \%)$ \\
\hline \multicolumn{7}{|l|}{ Organic disease history } \\
\hline Cardiovascular disease & 31 & 6 & 2 & 0 & 1 & $40(25 \%)$ \\
\hline $\begin{array}{l}\text { Chronic obstructive pulmonary } \\
\text { disease }\end{array}$ & 7 & 3 & 1 & 2 & 0 & $13(8.5 \%)$ \\
\hline
\end{tabular}

drowning in the sea was the cause of death in two men. Six victims died in railway accidents and one victim died of a gunshot wounds during a hunting accident. Table 6 illustrates the epidemiological data of these accidental deaths.

\section{Suicidal deaths}

In our study, we identified 16 cases of suicide. Seventy-five percent $(n=12)$ of the victims were male and the mean age was 71.1 years $( \pm 5.5)$. Suicidal deaths epidemiological data is illustrated in Table 1. Table 5 shows the distribution of suicidal deaths circumstances. A history of psychiatric disorders was elicited ten cases: depression $(n=5)$, schizophrenia $(n=4)$, and dementia $(n=1)$. Suicide in bereaved individuals was observed in two cases. A history of attempted suicide by slaughter and bleach poisoning was found in two victims, both schizophrenics. The suicide occurred in the victim's home in nine cases. The toxicological analyses in all suicide cases were negative. Hanging was the most used suicidal mean $(n=10)$. Suicidal drowning in a canal was observed in two cases. Blunt force resulting from jumping from a height was the cause of death in three victims: from the second floor of a house, in an empty well and from a bridge. A railway suicide was observed in one case. Table 7 shows the distribution of suicide deaths circumstances.

\section{Homicidal deaths}

Eight cases of homicide were recorded. The mean age of the victims was 73.2 years $( \pm 7.2)$. Death occurred in the victim's home in six cases and in a public place in two cases. Blunt trauma was the cause of death in five cases: a husband killed his 88 -year-old wife by a blunt object causing head trauma in a conjugal conflict and a son killed his 74-year-old father by a stick on the head in a context of a family conflict. Three men died of a cranio-thoracic blunt trauma; the context of these homicides could not be specified. Thermal burns were the cause of death in one case; the grandson killed his 83-year-old grandfather by immolating him by fire after spraying him with gasoline in a context of family conflict. Multiple means were used in two cases; the first case was a ligature strangulation associated with a craniofacial blunt trauma in a 74-year-old man by a 
Table 3 Distribution of domestic accidents epidemiological data

\begin{tabular}{|c|c|c|c|c|}
\hline & Falls $n(\%)$ & $\begin{array}{l}\text { Thermal } \\
\text { burns } n(\%)\end{array}$ & $\begin{array}{l}\text { Carbon monoxide } \\
\text { poisoning } n(\%)\end{array}$ & Total $n(\%)$ \\
\hline $\begin{array}{l}\text { Number of } \\
\text { cases }\end{array}$ & $38(58.4 \%)$ & $20(30.8 \%)$ & $7(10.8 \%)$ & 65 \\
\hline \multicolumn{5}{|l|}{ Age } \\
\hline $65-69$ & 6 & 8 & 3 & $17(26.2 \%)$ \\
\hline $70-74$ & 16 & 6 & 1 & $23(35.4 \%)$ \\
\hline $75-79$ & 11 & 2 & 2 & $15(23.1 \%)$ \\
\hline $80-84$ & 3 & - & 1 & $4(6.1 \%)$ \\
\hline$\geq 85$ & 2 & 4 & - & $6(9.2 \%)$ \\
\hline \multicolumn{5}{|l|}{ Gender } \\
\hline Male & 28 & 13 & 4 & $45(69.2 \%)$ \\
\hline Female & 10 & 7 & 3 & $20(30.8 \%)$ \\
\hline \multicolumn{5}{|l|}{ Marital status } \\
\hline Single & 16 & 5 & 1 & $22(33.8 \%)$ \\
\hline Married & 14 & 12 & 6 & $32(49.2 \%)$ \\
\hline Divorced & 3 & 3 & - & $6(9.3 \%)$ \\
\hline Widower & 5 & - & - & $5(7.7 \%)$ \\
\hline \multicolumn{5}{|l|}{ Season } \\
\hline Spring & 10 & 2 & - & $12(18.5 \%)$ \\
\hline Summer & 12 & 1 & - & $13(20 \%)$ \\
\hline Fall & 7 & 4 & - & $11(16.9 \%)$ \\
\hline Winter & 9 & 13 & 7 & $29(44.6 \%)$ \\
\hline $\begin{array}{l}\text { Cardiovascular } \\
\text { disease history }\end{array}$ & 11 & 5 & 1 & $17(26.2 \%)$ \\
\hline \multicolumn{5}{|c|}{ Mental disease history } \\
\hline Depression & 1 & 2 & - & $6(9.2 \%)$ \\
\hline Dementia & 3 & - & - & \\
\hline
\end{tabular}

family member in a context of family conflict. The second case was a manual strangulation associated with deep and extensive thermal burns and blunt head trauma in a 75-year-old man who witnessed a theft at a construction site on his way back home and was killed by the thief. Table 8 shows the distribution of homicide circumstances.

Table 4 Distribution of falls circumstances

\begin{tabular}{ll}
\hline & $n(\%)$ \\
\hline Traumatic injuries & \\
Head trauma & $33(87 \%)$ \\
Pelvic trauma & $5(13 \%)$ \\
Place of fall: stairs inside the house & $38(100 \%)$ \\
Place of death & \\
House & $34(89.5 \%)$ \\
Hospital & $4(10.5 \%)$ \\
\hline
\end{tabular}

Table 5 Distribution of thermal burns characteristics and circumstances

\begin{tabular}{ll}
\hline & $n(\%)$ \\
\hline Depth of burns & - \\
First-degree & - \\
Second-degree & $20(100 \%)$ \\
Third-degree & \\
Percentage of TBSA ${ }^{a}$ burned & $6(30 \%)$ \\
20-29\% & $8(40 \%)$ \\
30-39\% & $2(10 \%)$ \\
$40-49 \%$ & $1(5 \%)$ \\
$50-59 \%$ & $2(10 \%)$ \\
$60-69 \%$ & $1(5 \%)$ \\
$70-80 \%$ & \\
Burn sites & - \\
Head and neck only & - \\
Trunk only & - \\
Pelvis only & $3(15 \%)$ \\
Limbs only & $5(25 \%)$ \\
Trunk and limbs & $12(60 \%)$ \\
Head, neck, trunk, and limbs & \\
Source of fire & $11(55 \%)$ \\
Brazier & $6(30 \%)$ \\
\hline
\end{tabular}

${ }^{\mathrm{a}} T B S A$ total body surface area

Furthermore, we identified only one case where the manner of an unnatural death could not be determined. It was a man found charred in a forest.

\section{Discussion}

In Tunisia, from a legislative point of view, any violent or suspicious death poses an obstacle to the burial of the body and triggers a judicial inquiry and forensic autopsy with the aim of clarifying the cause of death and

Table 6 Epidemiological data of accidental deaths other than traffic and domestic accidents

\begin{tabular}{llll}
\hline & \multicolumn{2}{l}{ Gender } & $n(\%)$ \\
\cline { 2 - 3 } & Male & Female & \\
\hline Workplace accident & 3 & 0 & $5(35.7 \%)$ \\
$\quad$ Fall from height & 2 & 0 & \\
Blunt trauma & 2 & 0 & $2(14.3 \%)$ \\
Railway accident & 4 & 2 & $6(42.9 \%)$ \\
Hunting accident & 1 & 0 & $1(7.1 \%)$ \\
total & 12 & 2 & $14(100 \%)$ \\
\hline
\end{tabular}


Table 7 Distribution of suicidal deaths circumstances

\begin{tabular}{ll}
\hline Suicide circumstances & $n(\%)$ \\
\hline Place & $9(56.3 \%)$ \\
Private house & $4(25 \%)$ \\
Public place & $2(12.5 \%)$ \\
Canal & $1(6.2 \%)$ \\
Isolated place & \\
Motive of suicide & $10(62.5 \%)$ \\
Decompensation of a mental disease & $2(12.5 \%)$ \\
Bereavement & $4(25 \%)$ \\
Not specified & \\
Methods of suicide & $10(62.5 \%)$ \\
Hanging & $3(18.8 \%)$ \\
Fall from height & $2(12.5 \%)$ \\
Drowning & $1(6.2 \%)$ \\
Train trauma & \\
Psychiatric disorders & $5(31.2 \%)$ \\
Depression & $4(25 \%)$ \\
Schizophrenia & $1(6.2 \%)$ \\
Dementia &
\end{tabular}

determining the circumstances of its occurrence (Official Printing Office of the Republic of Tunisia 1957). The unnatural deaths of elderly are, however, likely to be underestimated. It is because of advanced age and a chronic somatic history that clinicians will sign death certificates without the request for investigations and that autopsies will then not be practiced in several cases of suspicious deaths (Kumar and Verma 2014).

Accidents account for the majority of unnatural deaths in elderly, followed by suicide and homicide (Kumar and Verma 2014; Eilertsen et al. 2006; Akar et al. 2014). Several

Table 8 Distribution of homicide circumstances

\begin{tabular}{ll}
\hline Homicide circumstances & $n(\%)$ \\
\hline Place & $6(75 \%)$ \\
Private house & $2(25 \%)$ \\
Public place & \\
Motive of homicide & $3(37.5 \%)$ \\
Family conflict & $1(12.5 \%)$ \\
Conjugal conflict & $1(12.5 \%)$ \\
Robbery & $3(37.5 \%)$ \\
$\quad$ Not specified & \\
Type of homicide & $5(62.5 \%)$ \\
Blunt trauma & $1(12.5 \%)$ \\
Multiple means: blunt trauma and mechanical asphyxia & $1(12.5 \%)$ \\
Multiple means: blunt trauma, burning and & $1(12.5 \%)$ \\
mechanical asphyxia & \\
Burning &
\end{tabular}

studies have focused on the safety of elderly people in public roads and suggest, through an analysis of risk factors, the establishment of means to protect them (Lucidi et al. 2014). In addition, injuries in the elderly proved to be more lethal than in the younger population, as even minimal lesions can be fatal (Kuhne et al. 2005) (Nagy et al. 2000). Accidents also lead to longer hospital stays, greater morbidity, complications, and readmissions (Lucidi et al. 2014) (Kuhne et al. 2005) (Subzwari et al. 2009). Elderly are people with a history of chronic diseases whose prevalence increases with age, and other dysfunctions that can impede their control of driving and can impair their ability to adapt to ever-changing urban streets (Kuhne et al. 2005). Cognitive impairments such as environmental memorization, visual disturbances, and decreased mobility and reflexes are dysfunctions that can be responsible for these dramatic ends (Eilertsen et al. 2006; Lucidi et al. 2014; Kuhne et al. 2005; Subzwari et al. 2009). Cognitive disorders were not described in our study for road accidents; however, sensory and motor impairments can be deduced from the presence of heavy and chronic antecedents. We observed that traffic accidents were more frequent on Monday but we could not determine the time of day at which they mostly occur. It has been reported, in a study conducted in Norway, that traffic accidents occur in the early morning and late afternoon due to a lower visibility (Eilertsen et al. 2006). As in our study, it was reported that pedestrians were older than drivers (Eilertsen et al. 2006). It is to note that driving while intoxicated is rare among the elderly, unlike the young population (Eilertsen et al. 2006). In our work, we have not seen any ethyl poisoning which is deleterious and plays an important role in the occurrence of traffic accidents but also drowning and falls (Eilertsen et al. 2006). This is probably due to the cultural and religious characteristics of our population, unlike other European studies. Unnatural deaths and specifically traffic accidents were higher in urban areas in this study. In contrast with these results were those obtained by Kumar and Verma in their study conducted in India (Kumar and Verma 2014).

Accidental falls are the leading cause of morbidity and mortality in the elderly (Stevens et al. 2008; John and Koelmeyer 2001). However, this varies by year and country where the studies are done. These are also the most costly accidents for health systems (World Health Organization 2007; Alamgir et al. 2012). The risk of falls increases with age (Alamgir et al. 2012; Peel 2011). The incidence would increase considerably particularly after the age of 80 (World Health Organization 2007). It is also described that falls would affect women more than men; this is explained by the difference in physical strength (Yoshida 2007) or comorbid conditions than women at the same age (World Health Organization 2007). A significant number of deaths are secondary to pulmonary embolism or pneumonia, which are complications of bed rest and immobilization 
due to fractures. These victims usually die in hospitals and their deaths can sometimes not be reported to the authorities leading to an underestimation of mortality due to falls (Eilertsen et al. 2006).

Burns with or without carbon monoxide poisoning accounted for $7.8 \%$ of the accidental deaths of elderly subjects in an American study (Homer et al. 2005) and 5.2\% of deaths in a Norwegian study (Eilertsen et al. 2006). They are described as the major cause of accidental death in the elderly (Zhu et al. 2000). It is generally held that the elderly are prone to burns because of age-related deterioration of judgment, cognition, and mobility (Liu et al. 2013) and it has been shown that the installation of smoke detectors greatly reduces the occurrence of such accidents (Homer et al. 2005). Fire sources in our study were rudimentary heating or cooking means such as brazier used for burning charcoal, and gas cylinders feeding stoves. This is also the case for carbon monoxide poisoning that was due in our population to gas leaks from a brazier which continues to be increasingly involved in burns and accidental poisoning especially in winter. Presence of comorbid pathologies and a total area burned beyond $20 \%$ are positively correlated with death (Middelkoop and Vloemans 2015). Burns often affect the extremities including the hands, followed by the head and neck and then the trunk. They occur at home, as in cases of falls and poisoning, because elderly spend more time at home because of decrease in activity after retirement and are therefore more prone to domestic accidents. Furthermore, these accidents occur particularly in winter; this is related to the use of heating means such as charcoal or kerosene, as reported in the study conducted in China by Liu et al. (2013).

The poisoning of the elderly, unlike our study, is reported to be more often suicidal than accidental in studies carried out in India and Norway (Kumar and Verma 2014; Eilertsen et al. 2006). We observed that accidental poisoning was especially caused by carbon monoxide and due the increased use of braziers in winter. In Turkey, Akar et al. (2014) found that carbon monoxide poisoning was the second cause of death in the elderly after traffic accidents, with $21.7 \%$ and $37.7 \%$ respectively. It is noteworthy that the fatal work-related accidents of the elderly found in our study are a rare entity and very little studied in the literature. This is a rather unusual cause of death in this population, the majority of whom are retired.

The suicides of the elderly are found to be more radical, more violent, with a stronger intention (Bergman Levy et al. 2011). Non-violent means are drug poisoning, carbon monoxide poisoning, and vital submersions found more often in young people (Pitkälä et al. 2000). Hanging is the most commonly used method, followed by firearms or drug poisoning according to studies carried out in Norway and Finland (Eilertsen et al. 2006; Pitkälä et al. 2000). This is explained by the easy accessibility of hanging (Chan et al.
2007). Suicide occurs most often in the victim's home and less frequently in public places or rest centers according to a study from Turkey (Akar et al. 2014). Male gender, retirement, social isolation, and psychiatric and somatic pathologies are predisposing factors (Akar et al. 2014; Pitkälä et al. 2000; Nomura et al. 2016). Neoplastic and neurological pathologies are particularly associated with a high risk of suicide (Pitkälä et al. 2000). Depressive disorders are more prevalent while addictive behaviors such as alcohol abuse are less common (Pitkälä et al. 2000). In addition, elderly people rarely reported suicidal thoughts to those around them. On the other hand, they present themselves to their treating physicians shortly before suicide with sleep disorder, anxiety, or depressive symptoms, which should not be trivialized. The diagnosis of a psychiatric pathology and the initiation of a treatment is indeed an effective means of prevention (Avci et al. 2017). Suicidal intoxications have not been observed in our work; the most frequently found toxic agents for some authors are antidepressants (Eilertsen et al. 2006) and for others carbamate and organophosphates (Kumar and Verma 2014).

The vulnerability of the elderly makes them also exposed to violence and homicide (Coelho et al. 2010). It is mistakenly assumed that they are respected in society and that they are protected in view of their age (Krienert and Walsh 2010). This phenomenon is increasingly encountered but still little studied (Krienert and Walsh 2010). Some American studies have shown a predominance of homicides by firearms, much less accessible in our country, with $50 \%$ of cases followed by blunt objects, then sharp tools, and finally mechanical asphyxia (Krienert and Walsh 2010; Collins and Presnell 2006). Another study from Portugal found a predominance of cranial and thoracic trauma by blunt object, as in our work, followed by sharp objects and then firearms (Coelho et al. 2010). Homicides occur most often in the victim's home and in the context of theft (Coelho et al. 2010; Krienert and Walsh 2010; Falzon and Davis 1998). In our study, it was family conflicts that motivated half of the homicides. It is reported that men are more at risk than women, more likely to be killed by strangers, while women are more frequently assaulted by a member of the family (Coelho et al. 2010). The mean age of the victims in our study was similar to that found in the literature (Coelho et al. 2010). It is important to note that the elderly in Tunisia have recently received special protection under the law, with an increase in the sentences for violence and crimes against them, as they are considered vulnerable due to advanced age (Official Printing Office of The Republic of Tunisia 2017).

The strength of our study is that it was carried on a representative sample of the Tunisian population. It determines the unnatural manner and causes of death in the elderly and analyzes the circumstances and epidemiological characteristics of these deaths. It allows to 
compare our data with international literature and it permits to carry out prevention strategies in order reduce the mortality of these vulnerable individuals. The most important limitation of this study is that the number of unnatural deaths may be underestimated due to cases that can be misclassified as natural deaths and that were not referred to the department of Legal medicine. Another limitation is that our study is retrospective, data were sometimes missing, and some information could not be specified.

\section{Conclusion}

Our study shows that elderly people are exposed, due to physiological, behavioral, environmental, and contextual factors, to unnatural deaths, particularly accidental deaths. In our aging population, as elsewhere in the world, we will increasingly face these accidents but also, less frequently, suicides and homicides. It should be mentioned that there are other causes of death described in the literature but not found in our population, such as hypothermia, drug poisoning, and medical malpractice, as well as other places of death such as nursing homes or detention centers. Our study identified several aspects similar to international research, with nevertheless particularities such as traumatic deaths in the workplace that are rare and poorly described or accidental carbon monoxide poisoning following the use of the charcoal brazier in confined spaces. Autopsies provide important statistical data on the causes and manners of death that can be used for preventive strategies. For instance, actions must be carried out on the maintenance of public roads and raising awareness among public road users. Preventive measures should also include home improvement to help the elderly avoid accidental falls, installing smoke detectors, and the non-use of defective or rudimentary heating. The specialization of care for the elderly on the somatic or psychiatric level given the specific needs should be considered as well.

\section{Acknowledgments}

None.

\section{Funding}

This research received no specific grant from any funding agency in the public, commercial, or not-for-profit sectors.

\section{Availability of data and materials}

The datasets analyzed during the current study are available from the corresponding author on reasonable request.

\section{Authors' contributions}

All authors have equally participated in this work. All authors read and approved the final manuscript.

Ethics approval and consent to participate

Ethical approval was declared by the ethics committee of the Faculty of Medicine, University Tunis El Manar, Tunis, Tunisia.

Consent for publication

Not required by the ethics committee.
Competing interests

The authors declare that they have no competing interests.

\section{Publisher's Note}

Springer Nature remains neutral with regard to jurisdictional claims in published maps and institutional affiliations.

Received: 5 September 2018 Accepted: 21 April 2019

Published online: 14 May 2019

\section{References}

Akar T, Karapirli M, Akcan R, Demirel B, Akduman B, Dursun AZ, Sari S, Özkök A (2014) Elderly deaths in Ankara, Turkey. Arch Gerontol Geriatr 59:398-402. https://doi.org/10.1016/j.archger.2014.05.005

Alamgir H, Muazzam S, Nasrullah M (2012) Unintentional falls mortality among elderly in the United States: time for action. Injury 43:2065-2071. https://doi. org/10.1016/j.injury.2011.12.001

Avci D, Selcuk KT, Dogan S (2017) Suicide risk in the hospitalized elderly in Turkey and affecting factors. Arch Psychiatr Nurs 31:55-61. https://doi.org/10. 1016/.apnu.2016.08.002

Bergman Levy T, Barak Y, Sigler M, Aizenberg D (2011) Suicide attempts and burden of physical illness among depressed elderly inpatients. Arch Gerontol Geriatr 52:115-117. https://doi.org/10.1016/j.archger.2010.02.012

Chan J, Draper B, Banerjee S (2007) Deliberate self-harm in older adults: a review of the literature from 1995 to 2004. Int J Geriatr Psychiatry 22:720-732. https://doi.org/10.1002/gps.1739

Coelho L, Ribeiro T, Dias R, Santos A, Magalhães T (2010) Elder homicide in the north of Portugal. J Forensic Legal Med 17:383-387. https://doi.org/10.1016/j. jflm.2010.05.010

Collins KA, Presnell SE (2006) Elder Homicide. Am J Forensic Med Pathol 27:183187. https://doi.org/10.1097/01.paf.0000203268.30433.01

Eilertsen HH, Lilleng PK, Maehle BO, Morild I (2006) Unnatural death in the elderly a forensic study from Western Norway. Forensic Sci Med Pathol 3:23-31. https://doi.org/10.1385/Forensic

Falzon AL, Davis GG (1998) A 15 year retrospective review of homicide in the elderly. J Forensic Sci 43:16148J. https://doi.org/10.1520/JFS16148J

Homer CD, Engelhart DA, Lavins ES, Jenkins AJ (2005) Carbon monoxide-related deaths in a metropolitan county in the USA: an 11-year study. Forensic Sci Int 149:159-165. https://doi.org/10.1016/j.forsciint.2004.06.012

John SM, Koelmeyer TD (2001) The forensic pathology of nonagenarians and centenarians: do they die of old age? (the Auckland experience). Am J Forensic Med Pathol 22:150-154. https://doi.org/10.1097/00000433200106000-00007

Krienert JL, Walsh JA (2010) Eldercide: a gendered examination of elderly homicide in the United States, 2000-2005. Homicide Stud 14:52-71. https:// doi.org/10.1177/1088767909352736

Kuhne CA, Ruchholtz S, Kaiser GM, Nast-Kolb D, Working group on multiple trauma of the German society of trauma (2005) Mortality in severely injured elderly trauma patients - when does age become a risk factor? World I Surg 29:1476-1482. https://doi.org/10.1007/s00268-005-7796-y

Kumar S, Verma A (2014) A study of elderly unnatural deaths in medico-legal autopsies at Lucknow locality. Med Sci Law 54:127-131. https://doi.org/10. $1177 / 0025802413502783$

Liu Y, Chen J-J, Crook N, Yu R, Xu X-W, Cen Y (2013) Epidemiologic investigation of burns in the elderly in Sichuan Province. Burns 39:389-394. https://doi.org/ 10.1016/j.burns.2012.04.012

Lucidi F, Mallia L, Lazuras L, Violani C (2014) Personality and attitudes as predictors of risky driving among older drivers. Accid Anal Prev 72:318-324. https://doi.org/10.1016/.aap.2014.07.022

Middelkoop E, Vloemans AFPM (2015) Response to burns in the elderly: what is pathophysiology and what is physiology? EBioMedicine 2:1314-1315

Nagy KK, Smith RF, Roberts RR, Joseph KT, An GC, Bokhari F, Barrett J (2000) Prognosis of penetrating trauma in elderly patients: a comparison with younger patients. J Trauma 49:190-3-4

National Institute of Statistics Tunisia- Institut National de la Statistique-Tunisie (2014). http://www.ins.nat.tn

Nomura M, McLean S, Miyamori D, Kakiuchi Y, Ikegaya H (2016) Isolation and unnatural death of elderly people in the aging Japanese society. Sci Justice 56:80-83. https://doi.org/10.1016/j.scijus.2015.12.003

Official Printing Office of the Republic of Tunisia. Official Gazette n¹02 of August 1st, 1957. Law $n^{\circ} 1957-3$ on civil status 
Official Printing Office of the Republic of Tunisia. Official gazette $n^{\circ} 65$ of august 15,2017 . Law n'2017-58 on violence against women

Peel NM (2011) Epidemiology of falls in older age. Can J Aging / La Rev Can du Vieil 30:7-19. https://doi.org/10.1017/S071498081000070X

Pitkälä K, Isometsä ET, Henriksson MM, Lönnqvist JK (2000) Elderly suicide in Finland. Int Psychogeriatr 12:209-220. https://doi.org/10.1017/ S1041610200006335

Stevens JA, Mack KA, Paulozzi LJ, Ballesteros MF (2008) Self-reported falls and fallrelated injuries among persons aged $\geq 65$ years-United States, 2006. J Saf Res 39:345-349. https://doi.org/10.1016/j.jsr.2008.05.002

Subzwari S, Desapriya E, Babul-Wellar S, Pike I, Turcotte K, Rajabali F, Kinney J (2009) Vision screening of older drivers for preventing road traffic injuries and fatalities. In: Subzwari S (ed) Cochrane database of systematic reviews. Wiley, Chichester

World Health Organization (2013) world health statistics. WHO Geneva

World Health Organization (2007) WHO global report on falls prevention in older age. Commun Health (Bristol) 53 doi: 9789241563536

Yoshida S (2007) A global report on falls prevention epidemiology of falls. WHO Geneva Rep 1-40

Zhu B-L, Oritani S, Ishida K, Quan L, Sakoda S, Fujita MQ, Maeda H (2000) Child and elderly victims in forensic autopsy during a recent 5 year period in the southern half of Osaka city and surrounding areas. Forensic Sci Int 113:215218. https://doi.org/10.1016/S0379-0738(00)00208-5

\section{Submit your manuscript to a SpringerOpen ${ }^{\circ}$ journal and benefit from:}

- Convenient online submission

- Rigorous peer review

- Open access: articles freely available online

- High visibility within the field

- Retaining the copyright to your article

Submit your next manuscript at $\boldsymbol{\nabla}$ springeropen.com 